\title{
Urbanization dramatically altered the water balances of a paddy field-dominated basin in southern China
}

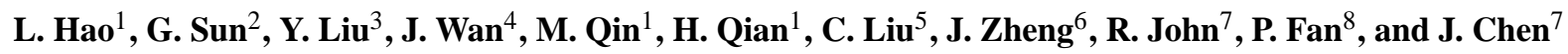 \\ ${ }^{1}$ International Center for Ecology, Meteorology, and Environment (IceMe), Jiangsu Key Laboratory of Agricultural \\ Meteorology, Nanjing University of Information Science and Technology (NUIST), Nanjing 210044, China \\ ${ }^{2}$ Research Hydrologist, Eastern Forest Environmental Threat Assessment Center, Southern Research Station, USDA Forest \\ Service, Raleigh, NC 27606, USA \\ ${ }^{3}$ Center for Forest Disturbance Science, Southern Research Station, USDA Forest Service, Athens, GA 30602, USA \\ ${ }^{4}$ China Institute of Water Resources and Hydropower Research, Beijing 100048, China \\ ${ }^{5}$ State Key Laboratory for Information Engineering in Surveying, Mapping and Remote Sensing, Wuhan University, \\ Wuhan 430079, China \\ ${ }^{6}$ College of Forestry, Sichuan Agricultural University, Chengdu, Sichuan, China \\ ${ }^{7}$ Center for Global Change and Earth Observations (CGCEO), and Department of Geography, Michigan State University, \\ East Lansing, MI 48823, USA \\ ${ }^{8}$ School of Planning, Design, and Construction (SPDC) and Center for Global Change and Earth Observations (CGCEO), \\ Michigan State University, East Lansing, MI 48823, USA
}

Correspondence to: G. Sun (gesun@fs.fed.us)

Received: 14 January 2015 - Published in Hydrol. Earth Syst. Sci. Discuss.: 13 February 2015

Revised: 4 July 2015 - Accepted: 8 July 2015 - Published: 31 July 2015

\begin{abstract}
Rice paddy fields provide important ecosystem services (e.g., food production, water retention, carbon sequestration) to a large population globally. However, these benefits are diminishing as a result of rapid environmental and socioeconomic transformations, characterized by population growth, urbanization, and climate change in many Asian countries. This case study examined the responses of stream flow and watershed water balances to the decline of rice paddy fields due to urbanization in the Qinhuai River basin in southern China, where massive industrialization has occurred during the past 3 decades. We found that stream flow increased by $58 \%$ and evapotranspiration (ET) decreased by $23 \%$ during 1986-2013 as a result of a threefold increase in urban areas and a reduction of rice paddy fields by $27 \%$. Both high flows and low flows increased significantly by about $28 \%$ from 2002 to 2013 . The increases in stream flow were consistent with the decreases in ET and leaf area index monitored by independent remote sensing MODIS (Moderate Resolution Imaging Spectroradiometer) data. Attribution analysis, based on two empirical models, indicated that land-use/land-cover change contributed
\end{abstract}

about $82-108 \%$ of the observed increase in stream flow from $353 \pm 287 \mathrm{~mm} \mathrm{yr}^{-1}$ during $1986-2002$ to $556 \pm 145$ during 2003-2013. We concluded that the reduction in ET was largely attributed to the conversion of cropland to urban use. The effects of land-use change overwhelmed the effects of regional climate warming and climate variability. Converting traditional rice paddy fields to urban use dramatically altered land surface conditions from an artificial wetlanddominated landscape to an urban land-use- dominated one, and thus was considered an extreme type of contemporary hydrologic disturbance. The ongoing large-scale urbanization of the rice paddy-dominated regions, in humid southern China and East Asia, will likely elevate storm-flow volume, aggravate flood risks, and intensify urban heat island effects. Understanding the connection between land-use/land-cover change and changes in hydrological processes is essential for better management of urbanizing watersheds in the rice paddy-dominated landscape. 


\section{Introduction}

Urbanization is a global phenomenon that poses profound threats to the local environment, society, and culture (Foley et al., 2005; McDonald et al., 2011). The most obvious direct consequence of urbanization is the altered hydrology and water balances that control the flows of energy and matter in watershed ecosystems (Paul and Meyer, 2001; Sun and Lockaby, 2012). In addition to the direct hydrologic impacts, indirect impacts of urbanization on local weather patterns (e.g., rainfall intensity and surface air temperature) are also becoming increasingly important in a changing climate (Yang et al., 2013).

It is widely known that urbanization elevates peak-flow rates (Brath et al., 2006; Du et al., 2012; Sun and Lockaby, 2012) as a result of increased impervious surfaces that promote quick surface runoff (Dietz and Clausen, 2008; Miller et al., 2014). However, the hydrologic response to urbanization is extremely variable (Jacobson, 2011; Caldwell et al., 2012), due to climatic differences and land-use change patterns across a watershed (Sun and Lockaby, 2012). Empirical data are still lacking information about changes in water balances and watershed hydrologic characteristics other than storm flow, such as total flow, low flow, and evapotranspiration (ET) (Dow and DeWalle, 2000; Boggs and Sun, 2011) in different physiographic settings (Barron et al., 2013). Previous studies rely heavily on simulation models (Kang et al., 1998; Kim et al., 2005, 2014; Sakaguchi et al., 2014). Controversies on the magnitude and underlying mechanisms of hydrologic responses to land conversion during urbanization remain in literature (Wang et al., 2009; He et al., 2009; Sun and Lockaby, 2012). In particular, data are scarce on the effects of converting paddy fields to other land uses, resulting in conflicting conclusions. For example, a simulation study in Taiwan suggested that rice paddy fields generated $55 \%$ lower total runoff and $33 \%$ lower peak flows than dry farms (Wu et al., 1997). However, another simulation study that used the HEC-HMS model for a rice paddy-dominated watershed in southern China found that an increase in impervious surface areas from 3 to $30 \%$ increased the peak-flow rate and storm volume (4-20\%), but had a very limited impact on total annual flow (<6\%) (Wang et al., 2009; Du et al., 2011, 2012) and thus long-term water balances.

The highly populated Yangtze River Delta (YRD) region covers about $2 \%$ of China's land mass, but provides over $18 \%$ of China's gross domestic product (Gu et al., 2011). The population increased by almost $13 \%$ in the past decade to 156 million in 2013, and has become China's most industrialized region and one of the global "hot spots" of economic and social development. As the "home of fish and rice", southern China's landscapes have been dominated by rice paddy fields for thousands of years. The original coastal wetlands have long been ditched, drained, and cultivated for growing rice and other crops. Rice paddy fields are major sources of food production and offer many other ecosys-

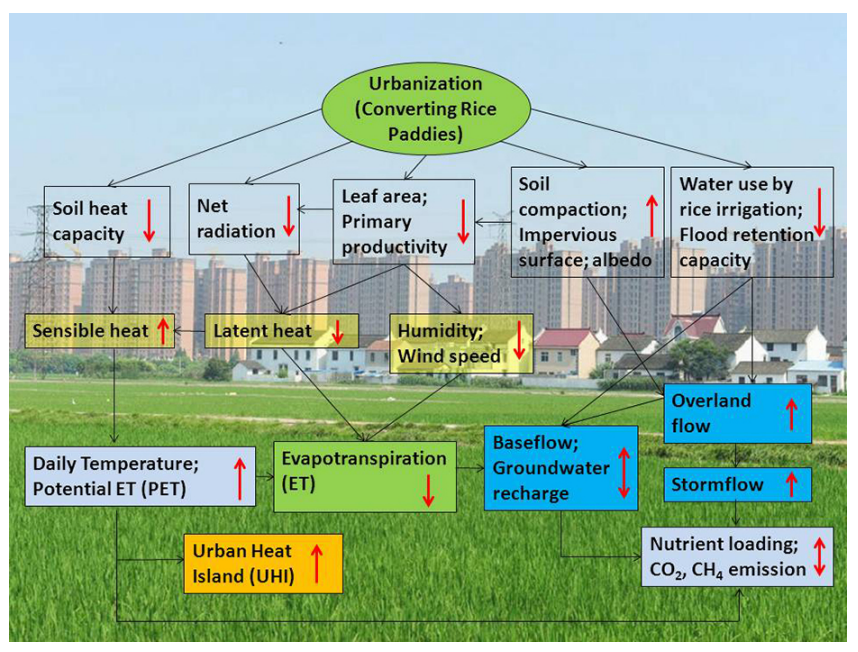

Figure 1. A conceptual model illustrating the potential hydrologic and environmental impacts of converting rice paddies to urban uses in the Yangtze River Delta region. Arrows represent directions (up or down or both) of change (background photo credit: http://blog. sciencenet.cn/blog-578415-712508.html).

tem services similar to wetlands including flood retention, groundwater recharge (He et al., 2009), nutrient cycling, and sequestration of greenhouse gases (Tsai, 2002). One study on ten typical rice paddies in China concluded that their ecosystem service values exceed their economic values three-fold (Xiao et al., 2011). The rapid urbanization and population rise in a warming climate in the YRD region has caused serious environmental and resource concerns such as overdrawing and pollution of groundwater, flooding, land subsidence, and urban heat islands (UHIs) (He et al., 2007; Gu et al., 2011; Zhao et al., 2014). The majority of the existing studies on paddy fields have focused on grain yield and irrigation, with little research on the hydrologic response of paddy fielddominated landscapes to urbanization (Du et al., 2011, 2012; Kim et al., 2014).

Converting paddies to urban land use has had many ripple effects on the local environment (Fig. 1). In particular, because rice paddy fields are rarely under water stress, the water loss or actual ET is close to the potential ET (Wu et al., 1997) and has been recognized as their cooling functions in regulating local climate (Xiao et al., 2011). In contrast, urban land use is generally characterized by low vegetation coverage with low ET and high runoff (Sun and Lockaby, 2012).

A study on China's 32 cities by Zhou et al. (2014) concluded that UHI effects dropped more sharply from urban centers to the rural areas in humid southern China than in northern China or inland cities, indicating the stronger contrast of the energy regime in the paddy-dominated regions than in other regions.

Therefore, we hypothesized that converting rice paddy fields to urban areas represents the maximum ET reduction possible among all common land-cover change sce- 


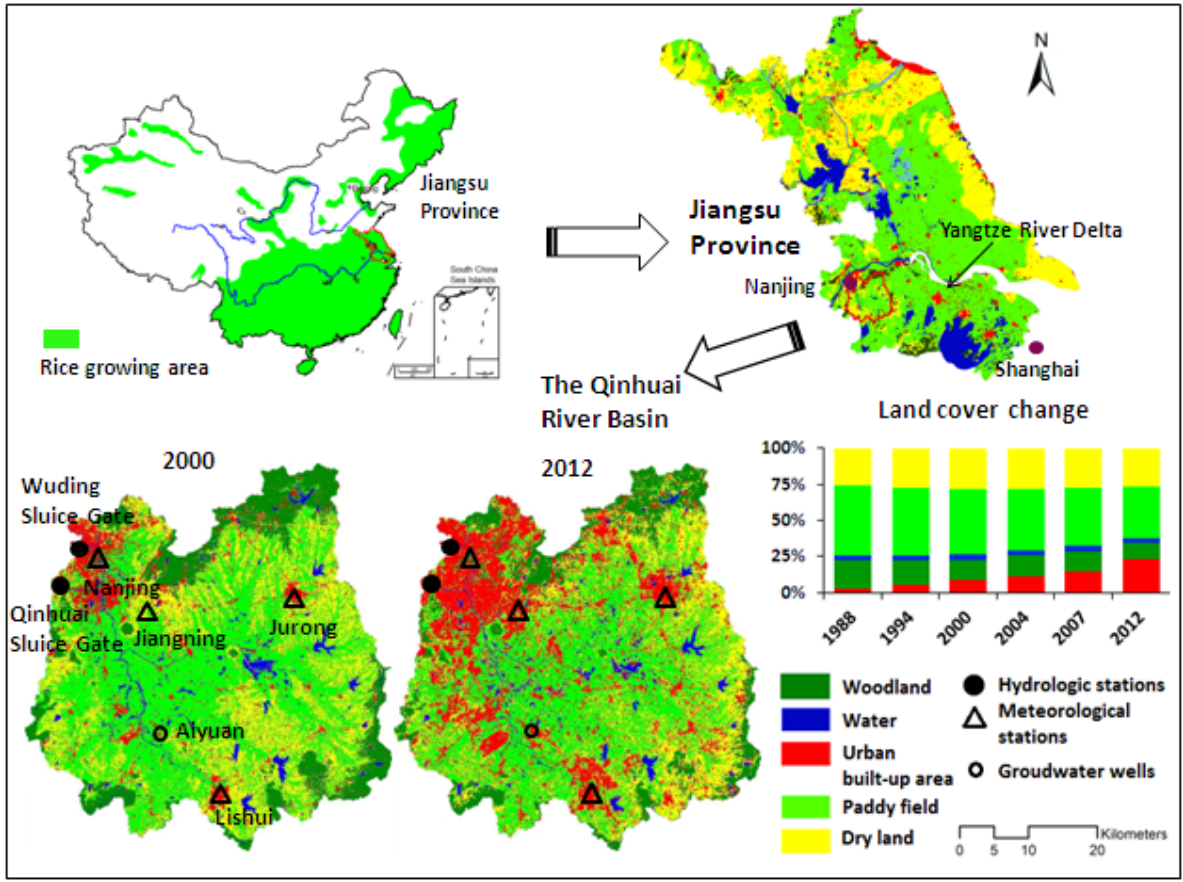

Figure 2. Watershed location, instrumentation, and land-use change patterns in the Qinhuai River basin, Yangtze River Delta in southern China. The insert map showing changes in land use derived from published data (Du et al., 2012; Chen and Du, 2014) (1988 and 1994) and Landsat 7 ETM+ images (2000-2012).

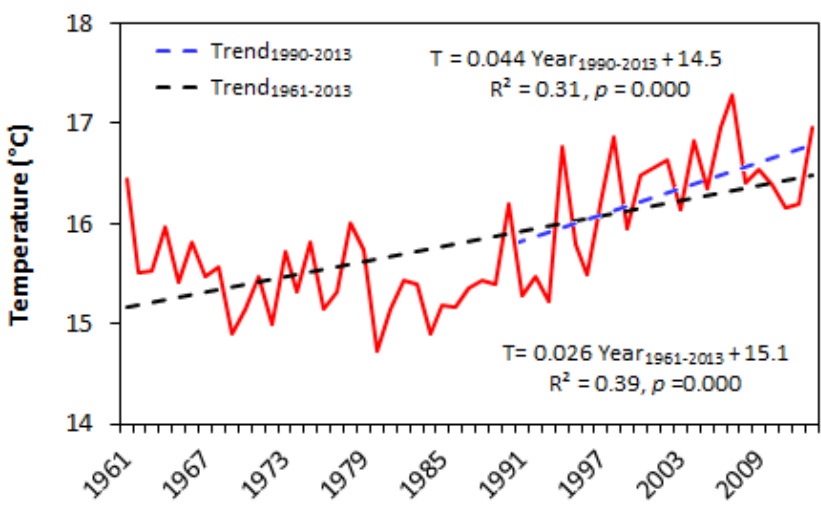

Figure 3. Mean annual air temperature change across four meteorological stations in the Qinhuai River basin in southern China during 1961-2013.

narios, potentially resulting in disproportionally higher impacts on water balances than other land conversion scenarios (e.g., converting dryland to urban uses). Along with the increase in impervious surface areas that are well known to increase storm flow, ET reduction during urbanization is likely to cause large impacts on the local micro-climate, stream flow, and water quality on paddy field-dominated watersheds (Fig. 1).

The overall goal of this study was to understand the processes underlining the hydrologic impacts of converting rice

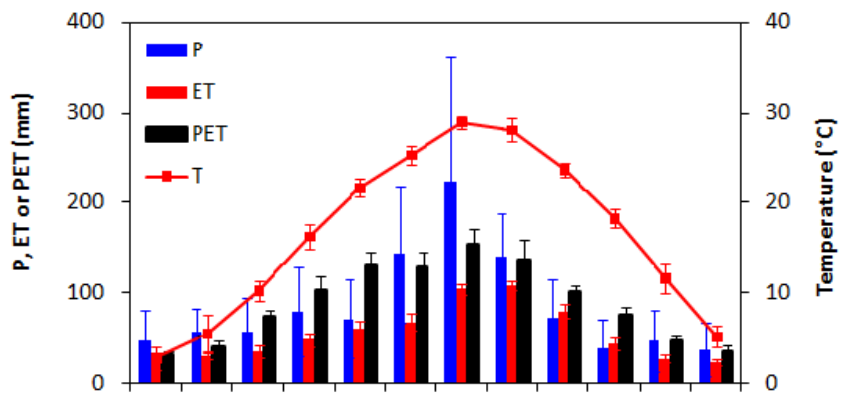

Jan Feb Mar Apr May Jun Jul Aug Sep Oct Nov Dec

Figure 4. Mean monthly precipitation $(P)$ (1986-2013), MODIS evapotranspiration (ET) (2000-2013), potential evapotranspiration (PET) (2000-2013) and temperature (T) (1986-2013). The vertical lines show standard deviation.

paddy fields to urban uses. The specific objectives of this study were: (1) to examine how urbanization in the past decade (2000-2013) has affected the water balances and hydrologic characteristics of the Qinhuai River basin (QRB), a typical landscape of the YRD (Fig. 2), (2) to test the hypothesis that urbanization in a paddy field-dominated watershed dramatically reduced ET, thus altered water balances, and (3) to explore the implications of urbanization for regional environmental change in southern China. In this study, we integrated long-term hydrometeorological monitoring data and remote sensing-based ET and vegetation products. Multiple 
advanced detection techniques were used to examine trends of climate and stream-flow overtime and their associations with biophysical variables, such as leaf area index and landuse dynamics.

\section{Methods}

\subsection{The Qinhuai River basin (QRB)}

As one of the tributaries of the Yangtze River, the QRB $\left(31^{\circ} 34^{\prime}-32^{\circ} 10^{\prime} \mathrm{N}, 118^{\circ} 39^{\prime}-119^{\circ} 19^{\prime} \mathrm{E}\right)$ has a catchment area of $2617 \mathrm{~km}^{2}$. The QRB represents a typical landscape of the lower Yangtze River Delta region that is characterized by its flat topography with natural river networks which are severely modified, and land use which is dominated by paddy rice fields, dotted with small irrigation ponds that have been converted from natural wetlands over thousands of years (Fig. 2). As the "backyard garden" of Nanjing City, the capital of Jiangsu province, the QRB is gradually being recognized for its important ecosystem services in drought/flood prevention, crop irrigation, recreation, tourism, and emergency drinking water supply to over 8 million residents. The local climate is controlled by the East Asia summer monsoon ( $\mathrm{Gu}$ et al., 2011). The multi-year mean air temperature is $15.4^{\circ} \mathrm{C}$. Mean air temperature (1961-2013) across the study basin increased drastically by a rate of $0.44^{\circ} \mathrm{C} \mathrm{decade}^{-1}$ from 1990 to 2013 (Fig. 3), suggesting an increasing trend in evaporative potential during the past 2 decades. The mean (1986-2013) annual precipitation is $1116 \mathrm{~mm}$, with $75 \%$ rainfall falling during April-October (Fig. 4). The observed long-term mean annual stream flow (per unit of area) is about $430 \mathrm{~mm}$, concentrated from June to August. The QRB has seen rapid urbanization during the past decade. The urban built-up areas increased from $9 \%$ $\left(222 \mathrm{~km}^{2}\right)$ to $12 \%\left(301 \mathrm{~km}^{2}\right)$ from 2000 to 2004 , but jumped to $23 \%\left(612 \mathrm{~km}^{2}\right)$ in 2012 , and the area of rice paddy fields decreased from $45 \%\left(1188 \mathrm{~km}^{2}\right)$ of the total land area in 2000 to $43 \%\left(1,112 \mathrm{~km}^{2}\right)$ in 2004 , and dramatically dropped to $36 \%\left(932 \mathrm{~km}^{2}\right)$ in 2012 (Fig. 2). Documents by Jiangsu Province Rural Statistics reported that the total area of rice planting in the QRB shrank more than $25 \%$ from $995 \mathrm{~km}^{2}$ in 2000 to $745 \mathrm{~km}^{2}$ in 2010.

\subsection{Land use, climate, stream flow, potential ET, ET, and leaf area index (LAI)}

We retrieved land-use and land-cover (LULC) data for four key time periods, 2000, 2004, 2007, and 2012, using Landsat TM and ETM+ images with a $30 \mathrm{~m}$ pixel resolution (http://glovis.usgs.gov/). We also compared our analysis to land-use and land-cover data acquired for the period from 1988 to 2012 from other multiple sources, including published theses and journal papers on the study basin (Du et al., 2012; Chen and Du, 2014). For land use in 2010, we also used the new Finer Resolution Observation and Monitoring of Global Land Cover that was created by Tsinghua University using Landsat TM and ETM+ data (Gong et al., 2013). The daily meteorological data (precipitation, radiation, temperature, wind speed, and humidity) for estimating potential ET were acquired from four standard climatic stations maintained by the local meteorological bureau across the QRB (Fig. 2). Stream-flow data with varying temporal resolutions were compiled from hydrologic records for two hydrological stations, the Wuding sluice gate (Wuding station thereafter) and the Inner Qinhuai sluice gate (Inner Qinhuai station thereafter), which controlled the outflows from the Qinhuai River and back flows from the Yangtze River (Fig. 2). The daily stream-flow data (2002-2003; 2006-2013) for the "flooding periods" from May to October recorded at the Wuding station were used to characterize high flows and low flows. The total annual stream flow discharged to the Yangtze River was the sum of flows measured at the Wuding station and the Inner Qinhuai station. Total annual streamflow data for the period of 1986-2006 were reported in Du et al. (2011) and we collected daily and monthly stream-flow data for other periods (Table 1).

Potential ET (PET) represents the maximum ecosystem evapotranspiration when soil water is not limited, such as for the case of paddy fields. PET represents a comprehensive index of availability of atmospheric evaporative energy that is controlled by radiation, temperature, humidity, and wind speed. Daily PET rates were calculated using the standard FAO 56 method and were averaged across the four climatic stations for the period 2000-2013 (Allen et al., 1994). The improved MOD16 data sets provide consistent estimates of global actual ET at an 8-day and $1 \mathrm{~km}^{2}$ resolution (Mu et al., 2011). Yuan et al. (2011) reprocessed the MODIS leaf area index (LAI) data sets using the modified temporal spatial filter (mTSF) and time-series analysis with the TIMESAT software (Jonsson and Eklundh, 2004) and provided reliable continuous LAI estimates from 2000 to 2013. Mean monthly PET and MODIS ET rates are presented in Fig. 4 along with other climatic variables to contrast seasonal ET, PET, and $P$ that controlled seasonal stream flow.

\subsection{Change detection}

Three statistical methods were used to comprehensively examine the temporal changes in the long-term hydro-climatic data series: (1) the Mann-Kendall test (Mann, 1945; Kendall, 1975) for the non-linear trend at significance levels of $\alpha=0.001,0.01,0.05$, and 0.10, (2) Sen's nonparametric method, applied to examine the linear trend and to estimate the true slope of an existing trend as change per year (Gilbert, 1987), and (3) the dynamic harmonic regression (DHR) method, used for determining the change rates for meteorological, hydrological, and LAI time series based on the Captain Toolbox (Taylor et al., 2007). The DHR model was used to fit three main components in a time series including the trend of the original time series, the periodicity, and 
Table 1. A summary of land use, climate, and hydrology data resources.

\begin{tabular}{|c|c|c|c|c|}
\hline Data type & Data resources & Data details & Periods & $\begin{array}{l}\text { Spatio-temporal } \\
\text { resolution }\end{array}$ \\
\hline Land use/land cover & $\begin{array}{l}\text { Landsat TM and ETM+ images (http:// } \\
\text { glovis.usgs.gov/) published theses and } \\
\text { journal papers; Du et al. (2012); Chen } \\
\text { and Du (2014); Gong et al. (2013) }\end{array}$ & Land-use/land-cover types & $\begin{array}{l}1988, \quad 1994, \quad 2000 \\
2004,2007 \text { and } 2012\end{array}$ & $30 \mathrm{~m}$ \\
\hline Climate & $\begin{array}{l}\text { Jiangsu meteorological bureau (four } \\
\text { meteorological stations) }\end{array}$ & $\begin{array}{l}\text { Precipitation, radiation, } \\
\text { temperature, wind speed, } \\
\text { and humidity }\end{array}$ & $1961-2013$ & Daily \\
\hline Stream flow & $\begin{array}{l}\text { Two hydrological stations: the Wuding } \\
\text { sluice gate and the Inner Qinhuai sluice } \\
\text { gate. Published journal papers; Du et } \\
\text { al. (2011) }\end{array}$ & Stream flow & $\begin{array}{l}2002-2003 \\
\text { (May-October), } \\
2006-2013 \\
\text { (May-October), } \\
1986-2006\end{array}$ & $\begin{array}{l}\text { Daily (2002-2003, } \\
\text { 2006-2013); } \\
\text { Annual (1986-2006) }\end{array}$ \\
\hline Groundwater & Aiyuan well station & Groundwater table depth & 2006-2013 & Monthly \\
\hline Actual ET & $\begin{array}{l}\text { Improved MOD16 data sets } \\
\text { Mu et al. (2011) }\end{array}$ & Actual ET & $2000-2013$ & $\begin{array}{l}8 \text {-day and } 1 \mathrm{~km}^{2} \text { res- } \\
\text { olution }\end{array}$ \\
\hline Leaf area index (LAI) & $\begin{array}{l}\text { Improved MODIS LAI data sets } \\
\text { (http://globalchange } \\
\text { bnu.edu.cn/research/lai) } \\
\text { Yuan et al. (2011) }\end{array}$ & LAI & $2000-2013$ & $\begin{array}{l}8 \text {-day and } 1 \mathrm{~km}^{2} \text { res- } \\
\text { olution }\end{array}$ \\
\hline
\end{tabular}

the residuals, which were referred to as Gaussian white noise for convenience. The key feature of the DHR model is its ability to characterize the seasonal or periodic components of time series data, so the method is suitable for analyzing time series with remarkable seasonal variations. The DHR model analyzes the seasonal or periodic component using a similar approach to Fourier analysis.

We used a series of common hydrologic detection methods to determine magnitude and timing of the effects of landuse change and climate change on stream flow (Ma et al., 2010; Tang et al., 2011; Wei and Zhang, 2010). The flow duration curve (FDC) (Vogel and Fennessey, 1993) and the double mass curve (DMC) methods (Wei and Zhang, 2010) were used to determine changes of stream-flow frequency in daily and annual stream flow, respectively, as a result of urbanization.

The trend of the base-flow component of the stream flow is one important indicator of change in soil water storage, i.e., soil moisture and groundwater conditions (Price et al., 2011). The base-flow index (BFI) program was used to separate the base flow from measured total daily stream flow (Wahl and Wahl, 1995). Our results showed that $N$, the number of days over which a minimum flow could be determined, was 7 days for the study basin (Fig. 5), suggesting that BFI (base-flow : stream-flow ratio) would not change to much shorter than 7 days. We used a value of 0.9 for the turning point factor $(f)$ to remove daily stream flow greater than $100 \mathrm{~m}^{3} \mathrm{~s}^{-1}$. Details of the methods to determine $N$ and $f$ can be found in Wahl and Wahl (1995).

\subsection{Attribution analysis}

Once the hydrologic change point was detected, we determined the individual contributions of climate and landcover/land-use change to the observed stream-flow change. We assumed that the observed stream-flow change $(\Delta Q)$ in the study basin could be explained by the sum of change in climate $\left(\Delta Q_{\text {clim }}\right)$ and change in land use/land cover (i.e., urbanization) $\left(\Delta Q_{\text {lulc }}\right)$ :

$\Delta Q=\Delta Q_{\text {clim }}+\Delta Q_{\text {lulc }}$

Then, the contribution of land cover/land use $(\% \Delta Q)$ can be estimated as

$\% \Delta Q_{\text {lulc }}=\left(\Delta Q-\Delta Q_{\text {clim }}\right) / \Delta Q \cdot 100$,

or $\% \Delta Q_{\text {lulc }}=\left(1-\Delta Q_{\text {clim }} / \Delta Q\right) \cdot 100$.

$\Delta Q$ represents the observed mean annual $Q$ in the second period $-Q$ in the reference period (i.e., $\bar{Q}_{0}$ ).

We used the climate elasticity model (CEM) and the rainfall-runoff model (RRM) to determine $\Delta Q_{\text {clim }}$ (Li et al., 2007). The CEM involved developing an empirical relationship between the deviation of $Q\left(Q_{0 i}\right)$ and deviations $P\left(P_{0 i}\right)$ and PET $\left(\mathrm{PET}_{0 i}\right)$ from the long-term means for the reference period:

$\frac{Q_{0 i}}{\bar{Q}_{0}}=\alpha \cdot \frac{P_{0 i}}{\overline{P_{0}}}+\beta \cdot \frac{\mathrm{PET}_{0 i}}{\overline{\mathrm{PET}_{0}}}$,

where $\alpha$ and $\beta$ were fitted "climate sensitivity" parameters derived from annual climate data for the reference period (1986-2002) in this study, as determined by the double mass 
Table 2. The conversion matrix for land-use change during 2000-2012 in the Qinhuai River basin.

\begin{tabular}{lrrrrrc}
\hline \multirow{2}{*}{$2000\left(\mathrm{~km}^{2}\right)$} & \multicolumn{5}{c}{$2012\left(\mathrm{~km}^{2}\right)$} \\
\cline { 2 - 7 } & Dry crop lands & Paddy fields & Forest & Water & $\begin{array}{l}\text { Urban built- } \\
\text { up areas }\end{array}$ & $\sum$ \\
\hline Dry crop lands & & & & & & \\
Paddy fields & 320 & 226 & 7 & 8 & 175 & 736 \\
Forest & 257 & 681 & 6 & 24 & 220 & 1188 \\
Water & 74 & 2 & 264 & 2 & 24 & 366 \\
Urban built-up areas & 16 & 12 & 2 & 59 & 14 & 104 \\
$\sum$ & 26 & 13 & 3 & 3 & 178 & 223 \\
Area change from 2000 to 2012 $\left(\mathrm{km}^{2}\right)$ & 693 & 933 & 283 & 96 & 611 & 2617 \\
Area change from 2000 to 2012(\%) & -43 & -255 & -83 & -8 & 388 & - \\
\hline
\end{tabular}

Table 3. Summary of $Z$ statistics by the Nonparametric Mann-Kendall trend tests for temperature $(T)$, ET, PET, precipitation $(P)$, and LAI during the periods of July-August, April-October, and annual, Qinhuai River basin (2000-2013).

\begin{tabular}{llllll}
\hline Periods & \multicolumn{5}{c}{$Z$ statistic } \\
\cline { 2 - 6 } & LAI(s) & ET(s) $(\mathrm{mm})$ & PET(s) $(\mathrm{mm})$ & $P(\mathrm{~s})(\mathrm{mm})$ & $T(\mathrm{~s})\left({ }^{\circ} \mathrm{C}\right)$ \\
\hline July-August & $-2.41^{*}(-0.04)$ & $-2.3^{*}(-1.7)$ & $1.3(2.4)$ & $1.31(12.9)$ & $1.31(0.07)$ \\
April-October & $-2.30^{*}(-0.02)$ & $-1.2(-2.4)$ & $2.4^{*}(5.1)$ & $0.11(2.6)$ & $0.77(0.02)$ \\
Annual & $-2.08^{*}(-0.01)$ & $-1.5(-3.6)$ & $2.5^{*}(7.5)$ & $-0.55(-8.0)$ & $0.00(-0.00)$ \\
\hline
\end{tabular}

* Denotes significance level of 0.05 .

"s" is the true slope of the linear trend, i.e., change per year.

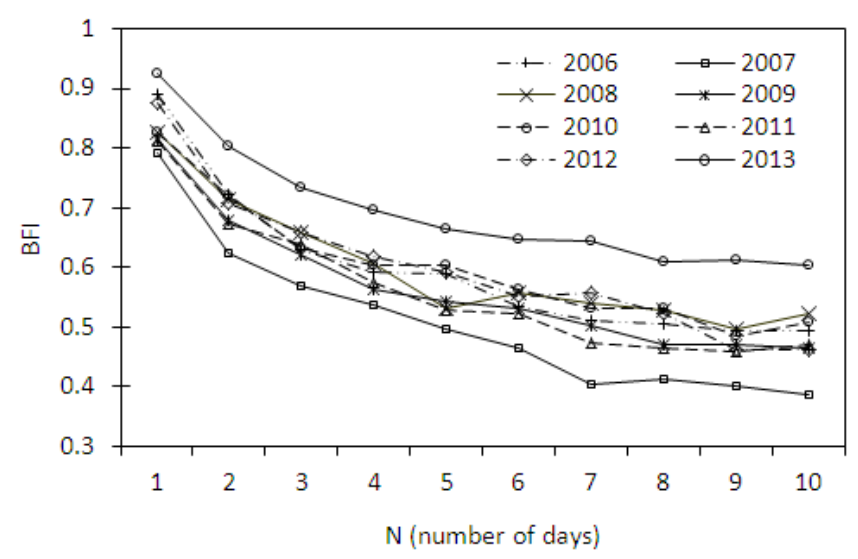

Figure 5. Sensitivity of base-flow index (BFI) to the number of days $(N)$ used to select the minimum value in base-flow separation analysis from 2006 to 2013 at the Wuding station located at the outlet of the Qinhuai River basin.

method while $\overline{Q_{0}}$ and $\overline{P_{0}}$ represented mean measured annual stream flow and precipitation. $\overline{\mathrm{PET}_{0}}$ represents mean annual potential ET estimated by the FAO reference ET method (Allen et al., 1994). Then, the effects of climate change in the second period in question could be calculated as where $\Delta \bar{Q}_{\text {clim }}$ represents the mean effects of climate change on annual stream flow during the second period, $\bar{Q}_{\text {pre }}$ predicts mean stream flow using the climate ( $P$ and PET) for the second period and the empirical equation developed from the reference period, and $\bar{Q}_{0}$ represents observed stream flow during the reference period, respectively.

The second method rainfall-runoff model (RRM) was chosen to strengthen the attribution analysis by considering the seasonal climatic variability. This method involved developing the relationships between $Q, P$, and the variances $\left(\sigma_{0 i}^{2}\right)$ of $P$ calculated using monthly $P$ data series without consideration of PET (Jones et al, 2006; Li et al., 2007):

$Q_{0 i}=a+b P_{0 i}\left(\sigma_{0 i}^{2}\right)^{c}$,

where $Q_{0 i}$ and $P_{0 i}$ are the annual $Q$ and $P$ for the reference period, respectively, while $\sigma_{1}^{2}$ is the variance of the monthly $P$. The values of the three parameters, $a, b$, and $c$ were derived using data from the reference period. The empirical model was then applied to estimate annual stream flow using precipitation for the second period $\left(Q_{\text {pre }}\right)$ and finally to calculate the mean changes in $Q\left(\Delta \bar{Q}_{\text {clim }}\right)$ as the differences between $\bar{Q}_{\text {pre }}$ and mean stream flow for the reference period $\left(\bar{Q}_{0}\right)$.

$\Delta \bar{Q}_{\text {clim }}=\bar{Q}_{\text {pre }}-\bar{Q}_{0}$, 
Table 4. Modeled contributions of land-use change and climate change to the increase in stream flow ( $\left.\mathrm{mm} \mathrm{yr}^{-1}\right)$ by the climate elasticity model (CEM) and rainfall-runoff model (RRM).

\begin{tabular}{|c|c|c|c|c|c|c|c|c|}
\hline \multirow[t]{2}{*}{ Period } & \multirow[t]{2}{*}{$\bar{P}$} & \multirow[t]{2}{*}{$\overline{\mathrm{PET}}$} & \multirow[t]{2}{*}{$\bar{Q}$} & \multirow[t]{2}{*}{$\Delta Q_{0}$} & \multicolumn{2}{|c|}{$\begin{array}{c}\operatorname{CEM}(\alpha=0.27 \\
\quad \beta=-0.65)\end{array}$} & \multicolumn{2}{|c|}{$\begin{array}{c}\mathrm{RRM}(a=-509 \\
b=0.45 ; c=0.064)\end{array}$} \\
\hline & & & & & $\Delta \bar{Q}_{\text {clim }}$ & $\Delta \bar{Q}_{\text {lulc }}$ & $\Delta \bar{Q}_{\mathrm{clim}}$ & $\Delta \bar{Q}_{\text {lulc }}$ \\
\hline 1986-2002 (reference) & $1105 \pm 291$ & $998 \pm 82$ & $353 \pm 287$ & - & & & & \\
\hline 2003-2013 & $1134 \pm 178$ & $1075 \pm 45$ & $556 \pm 145$ & 203 & $-15 \pm 23$ & $218 \pm 131(108 \%)$ & $36 \pm 169$ & $167 \pm 100$ \\
\hline
\end{tabular}

\section{Results}

\subsection{Land conversion and change in LAI}

During 2000-2012, the QRB went through dramatic landcover changes characterized by an increase in urban areas and a decrease in paddy fields (Du et al., 2011, 2012; Chen and Du, 2014) (Fig. 2). The land-cover change matrix shows that, from 2000 to 2012, the area of urban built-up areas increased $388 \mathrm{~km}^{2}$ or $174 \%$ at the expense of dry crop lands (decreased $43 \mathrm{~km}^{2}$, or $6 \%$ ), paddy fields (decreased $255 \mathrm{~km}^{2}$, or $21 \%$ ), and forest lands (decreased $83 \mathrm{~km}^{2}$, or $23 \%$ ) (Table 2). Since dryland changed relatively slightly from 2000 to 2012 (Fig. 2 and Table 2), the majority of detected reduction in cropland area came from the changes in paddy fields.

MODIS data indicated that both mean annual and peak growing season watershed level LAI decreased significantly $(p<0.05)$ with $Z$ statistic of -2.08 and $Z$ statistic of -2.41 , respectively (Table 3) (Fig. 6). Since the major decrease in land use was paddy rice, the decline of LAI was mainly caused by land conversion of paddy field to urban uses. The decrease trend of LAI followed a similar pattern as ET during 2000-2013.

\subsection{Trend in climate and MODIS ET}

The $\mathrm{M}-\mathrm{K}$ test showed that the growing season precipitation had a weak increasing trend, but annual total precipitation had an insignificant decreasing trend during 2000-2013 (Table 3). The mean annual air temperature showed an insignificant change, but with an weak increase of $0.07^{\circ} \mathrm{C} \mathrm{yr}^{-1}$ in the peak growing season from July to August (Table 3). Both annual and growing season PET rose significantly by $7.5 \mathrm{~mm} \mathrm{yr}^{-1}$ (Z statistic $\left.2.5, p<0.05\right)$ and $5.1 \mathrm{~mm} \mathrm{yr}^{-1}(\mathrm{Z}$ statistic $2.4, p<0.05)$, respectively, an opposite trend of the actual ET (Table 3 ). The DHR method also identified a rising trend for annual PET.

The mean annual MODIS ET was $655 \mathrm{~mm} \mathrm{yr}^{-1}$, varying from a low of $598 \mathrm{~mm} \mathrm{yr}^{-1}$ in 2011 to the highest $715 \mathrm{~mm} \mathrm{yr}^{-1}$ in 2002 during the study period (20002013). Annual ET exhibited a general decreasing trend $\left(-3.6 \mathrm{~mm} \mathrm{yr}^{-1}\right)$ and pronounced decreases in the peak growing season of July to August $\left(-1.7 \mathrm{~mm} \mathrm{yr}^{-1}, Z\right.$ statistic $-2.3, p<0.05$ ) (Table 3) (Fig. 4). The ET linear trend during the peak growing season (July-August) accounted for

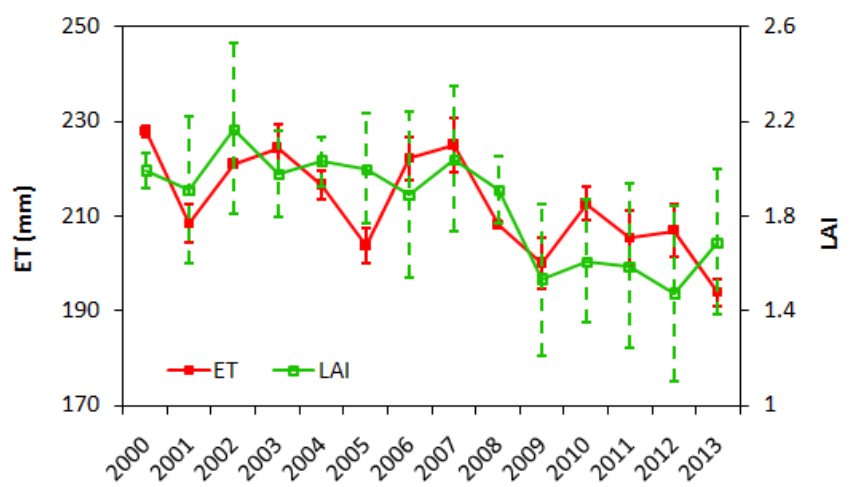

Figure 6. Total MODIS ET (mm per 2 months) and mean LAI during the peak growing season (July-August) over 2000-2013 in the Qinhuai River basin. Vertical lines represent standard deviation across space.

$32 \%$ of the total annual trend. Overall, ET showed a similar decreasing trend to LAI in the peak growing season during 2000-2013 (Fig. 6). Annual ET and the peak growing season ET departures from the long-term means had significantly positive correlations with LAI departures $(R=0.46$, $p=0.1 ; R=0.64, p=0.015$, respectively), but weak negative correlations with PET departures $(R=-0.38, p=0.18)$ during 2000-2013 (Fig. 7).

\subsection{Changes in stream-flow characteristics}

The FDC analysis for the flow measured at Wuding sluice gate indicated that both daily high flows and low flows were elevated during 2009-2013 compared to 2002-2008, with the median flow rates increased from $30 \mathrm{~m}^{3} \mathrm{~s}^{-1}$ to $38 \mathrm{~m}^{3} \mathrm{~s}^{-1}$ (Fig. 8). The extreme high flow in 2002-2008 was caused by one extreme rainfall event in July 2007 (rainfall was $339 \mathrm{~mm}$ ) that resulted in widespread flooding. The base-flow analysis also showed a significant $(p=0)$ increasing trend during 2006-2013 (Fig. 9). The increase in base flow or low flow coincided with the observations that the groundwater levels in the study basin were on the rise in recent decades as a result of groundwater management and likely land-use change in recent decades (Fig. 10). The runoff coefficient (stream flow : precipitation ratio) during the May-October period (wet, flooding seasons) increased significantly from 0.32 to 

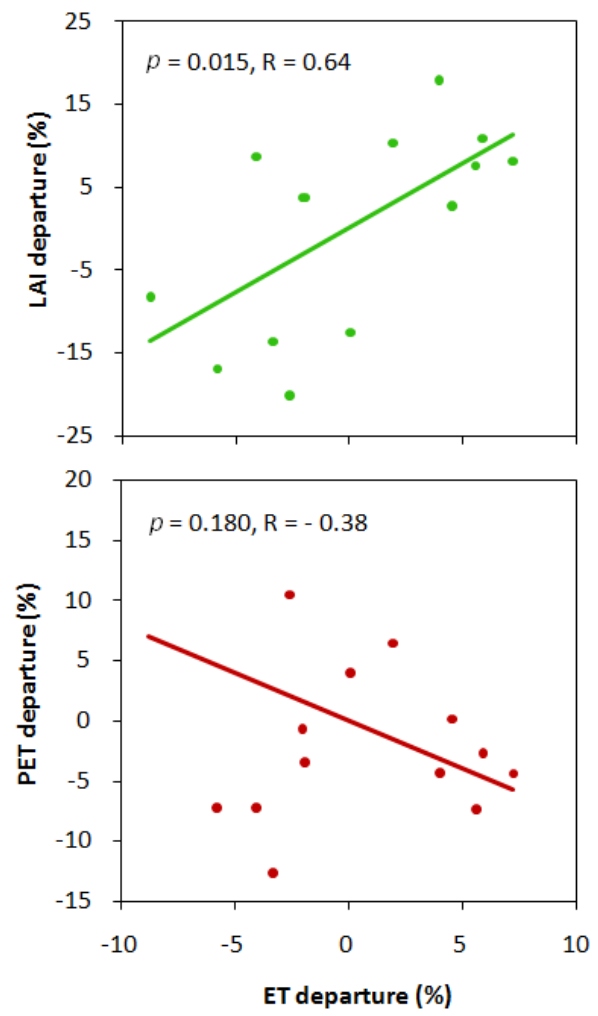

Figure 7. Correlations of the departures of basin-level ET with (a) the departures of mean leaf area index (LAI) and (b) the departures of PET in the peak growing season (July-August) over 20002013 in the Qinhuai River basin.

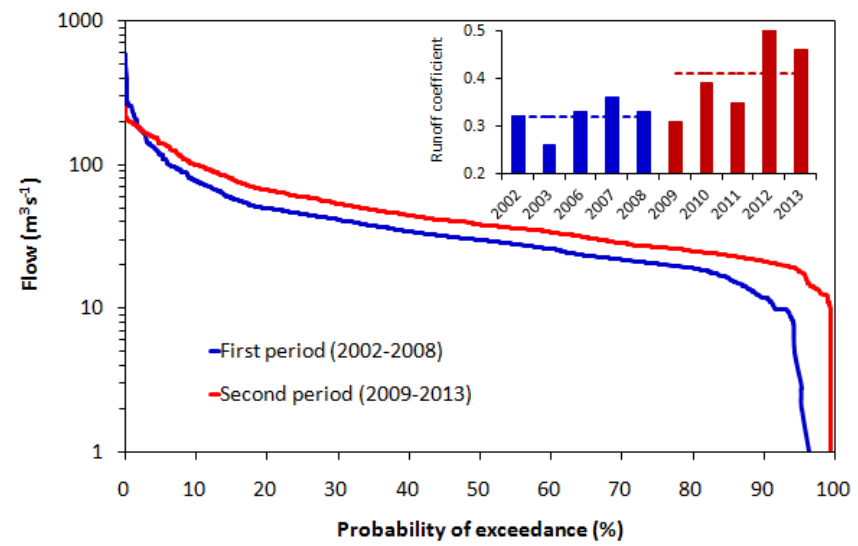

Figure 8. Flow duration curves for mean daily flow in the first period (2002-2003 and 2006-2008) and the second period (20092013) (May-October) measured at the Wuding station in the Qinhuai River basin. The insert shows the runoff coefficient, the ratio of stream flow/precipitation for the period from May to October when the flow control gate was open.

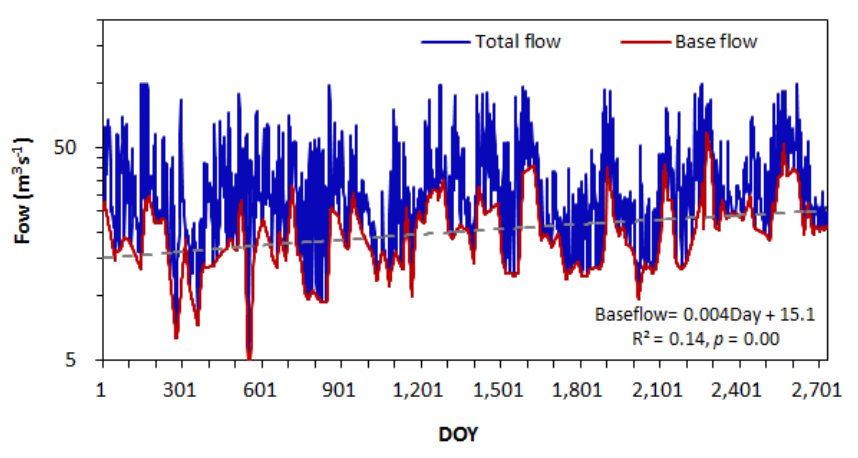

Figure 9. Trend of daily base flow separated from total stream flow measured at the Wuding station during 2006-2013. DOY (day of year) is the number of accumulated days since 1 January 2006.

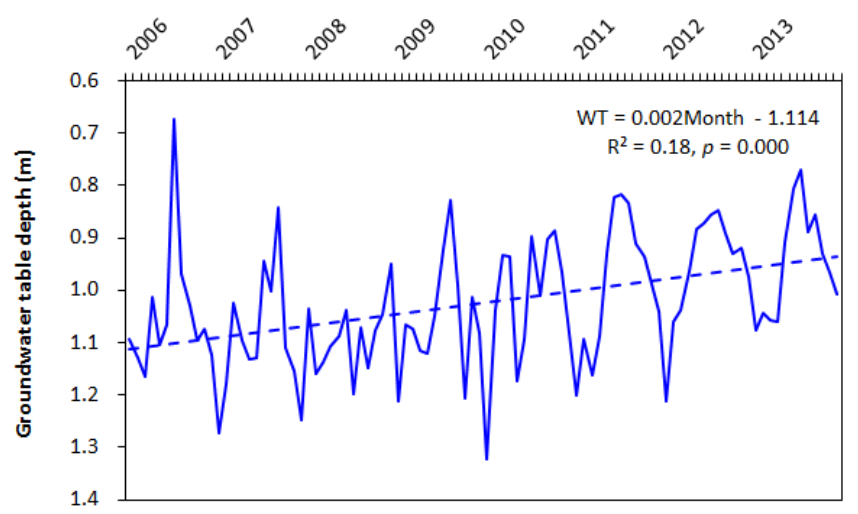

Figure 10. The trend of monthly groundwater table depth fluctuations measured at the Aiyuan well station in the Lishui subbasin during 2006-2013.

0.41 , or $28 \%$, during $2002-2013$ (Z statistic $2.89, p<0.01$ ) (Fig. 8).

\subsection{Changes in annual watershed water balances}

The DMC analysis identified a clear "break point" of total annual stream flow $(Q)$ around 2003 (Fig. 11). The slopes of the regression lines between accumulated precipitation and stream flow increased from 0.27 to 0.50 . Mean annual stream flow significantly increased from $353 \mathrm{~mm}$ to $556 \mathrm{~mm}$ from period 1 (1986-2002) to period 2 (2003-2013) (Fig. 12). This represents an increase in runoff coefficient $(Q / P)$ from 0.32 to 0.49 , a $53 \%$ increase. The trend of annual stream flow was influenced heavily by the year 1991; a huge flooding event occurred in the Yangtze River basin. When this year was removed, $R^{2}$ increased from 0.1 to 0.34 and $p$ value increased to a highly significant level $(p=0.002)$. In the meantime, annual ET as estimated by $P-Q$, decreased significantly from $752 \mathrm{~mm}$ to $578 \mathrm{~mm}$ from period 1 to period 2 , representing a decline in ET by $23 \%$ or an ET / $P$ ratio of $25 \%$. 


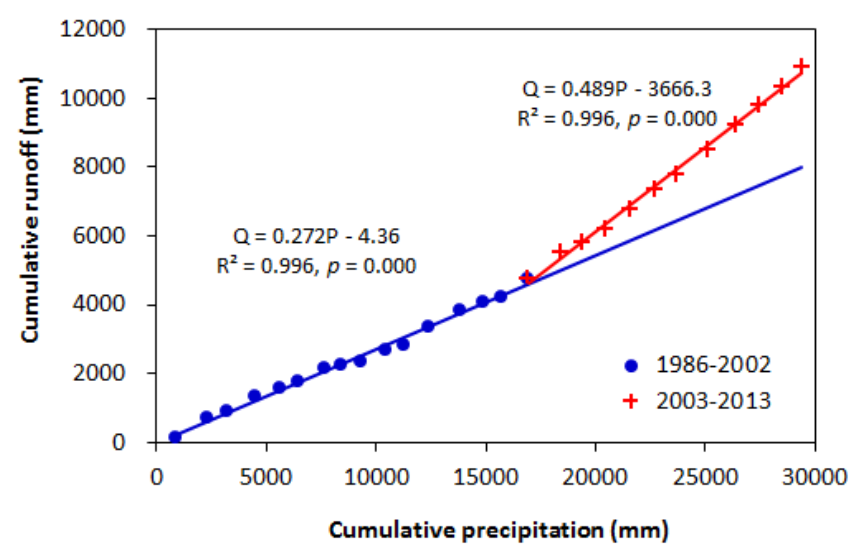

Figure 11. Double mass curves showing the relationships between accumulated annual precipitation $(P)$ and total stream flow $(Q)$ for the Qinhuai River basin (1986-2013). The extreme wet year of 1991 was removed from the analysis.

\subsection{Contributions of LULC change and climate change and variability}

The two models gave consistent results on the contributions of climate change $\left(\% \Delta Q_{\text {clim }}\right)$ and LULC change $\left(\% \Delta Q_{\text {lulc }}\right)$ to the observed annual increase $(203 \mathrm{~mm})$ in stream flow from the reference period of 1986-2002 to the evaluation period 2003-2013 (Table 4). The CEM model results suggested that the combinations of $P$ and PET caused a decrease of stream flow and the contribution of climate was negative $(-8 \%)$. Thus the contribution of LULC was positive $(108 \%)$, more than $100 \%$. In contrast, the RR model that did not include PET as a climatic factor suggested $P$ alone contributed $18 \%$ to the increase of stream flow while LULC change contributed $82 \%$. The modeling results indicate that PET is an important factor in evaluating the impacts of climate and LULC change. Hydrologic change in the study basin was controlled by both precipitation and PET. It appears that the effects of PET on stream flow (reducing flow) exceeded the influence of $P$ (increasing flow). Without considering the long-term change in air temperature, the contribution of LULC might have been underestimated in this study.

\section{Discussion}

\subsection{Increased stream flow explained by the decreases in ET and LAI}

The total stream flow (Fig. 12, Table 4), high flows, and low flows (Figs. 8, 9) in the QRB substantially increased during 2000-2013 while both LAI and ET decreased (Figs. 6, 12). Based on the watershed balance theory and comprehensive analyses using different methods, including FDC, CEM, and RRM, we attributed the dramatic increase in stream flow

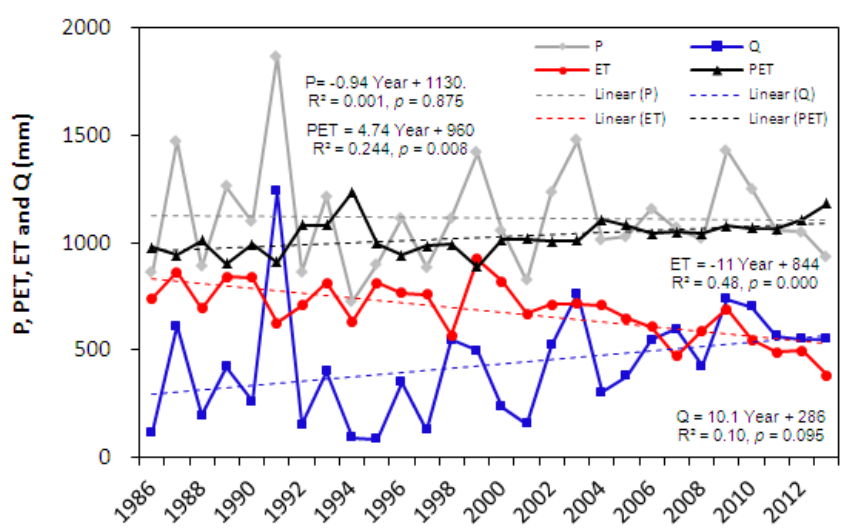

Figure 12. Trend of annual water balance and potential evapotranspiration (PET) for the Qinhuai River basin from 1986-2013. ET was estimated as the difference between precipitation $(P)$ and measured stream flow $(Q)$.

mainly to the changes in LULC and associated decrease in LAI, not climate (PET or $P$ ), for the following three complementary reasons.

First, LAI is a major controlling factor for ET, especially during the growing season (Sun et al., 2011a, b; Sun and Lockaby, 2012) and in humid, energy-limited southern China in particular (Liu et al., 2013). The strong relationship between MODIS ET and LAI (Figs. 6, 7) supported our hypothesis that urbanization dramatically reduced ET due to the reduction of LAI, thus the observed increase in stream flow is explained.

Second, regional annual ET is generally controlled by PET, $P$, and land surface conditions (Sun et al., 2005). A decrease in ET is normally caused by a decrease in $P$ and/or PET (Sun et al., 2005; Sun et al., 2011a, 2011b). Our data suggested that the decrease in ET was not caused by PET or $P$ because annual and growing-season PET significantly increased and overall precipitation did not change significantly. In fact, a negative correlation was found between ET and PET departures (Fig. 7). The DMC method that eliminated precipitation effects on stream flow suggested the QRB had a shift of annual stream flow upward around 2003 (Fig. 11). The two models for climate attribution analysis converged indicting that LULC contributed about $85 \%$ of the observed variability in stream flow and precipitation contributed about $15 \%$. PET increased more dramatically during 2003-2013 than during 1986-2002 (Fig. 12). The increase in PET might have masked the decrease of ET due to the change in LULC, so we argue that the estimated $85 \%$ contribution from LULC is a conservative estimate.

Third, the large decrease in LAI, as detected by remote sensing, corresponds closely to the dramatic conversion of rice paddy fields and an increase in total impervious area (TIA) during the urbanization campaign in the QRB since the early 2000s. Previous studies in the United States sug- 
gest that stream flow and water quality regimes are degraded when the TIA exceeds 10-20\% of the total watershed area (Arnold and Gibbons, 1996; Bledsoe and Watson, 2001). Our study result was consistent with the finding of the threshold response in literature, perhaps in the lower end of the spectrum $(<10 \%)$. The detected decrease in LAI due to shrinking rice paddy areas has overwhelmed the impacts of climate change (i.e. rise of PET) on ET, highlighting the importance of LULC change in evaluating environmental change in the study region.

\subsection{Regional hydrologic and environmental implications}

Our findings complement findings from an earlier study of the same basin. Du et al. $(2011,2012)$ conducted a simulation study suggesting that the elevated high flow was mostly due to an increase in impervious surface area. Our new analysis suggested that in addition to the increase in impervious surface areas, other factors such as reduced ET could be the main causes that contributed to the observed increase in total flow and base flow in the study basin. The present study advanced the understanding of the processes of hydrologic disturbances. Study results had important hydrological and environmental implications for paddy field-dominated regions in China and elsewhere in East Asia.

First, we confirmed our hypothesis that converting water stress-free paddy fields to relatively 'dry' urban uses or impervious surfaces dramatically reduced ET (Fig. 1). Thus, converting wetlands, such as paddy fields, to impervious or built-up areas is expected to have a much higher magnitude of hydrologic impacts than for converting dry croplands or forests to urban land uses (Tsai, 2002; Boggs and Sun, 2011). The ET estimates based on two independent methods, watershed water balance and remote sensing, all showed large decreases in ET.

Second, the populated study region is prone to floods and droughts due to the nature of a strong summer monsoon climate (Gu et al., 2011). Urbanization is likely to exacerbate the flood risks during the monsoon season as a result of decreased ET, an increased impervious surface area, and decreased retention capacity (Kang et al., 1998; Kim et al., 2014). In addition, an increase in storm flow causes important concerns for stream channel stability, soil erosion, and reactivation of stream bed sediment and pollutants (Sun and Lockaby, 2012). This is of particular concern given the increasing trend of typhoon activities in southern China under climate change (Gu et al., 2011).

Third, the increasing trend in base flow found in this study is in somewhat contradiction to popular literature that suggests otherwise (Ott and Uhlenbrook, 2004; Kim et al., 2005; Price et al., 2011). We argue that the large reduction in ET from paddy fields might have overwhelmed the reduction of groundwater recharge from the increased impervious surfaces. The QRB is still dominated by croplands $(62 \%$ of land area in 2012) and the dramatic reduction in water loss from rice cultivation and irrigation needs likely elevated groundwater recharge from uplands or stream channels overall (Fig. 10). Other studies have shown that reductions in forest land coverage, thus reduction in ET, could increase base flow in the humid piedmont region in North Carolina (Boggs and Sun, 2011) and northeastern US (Lull and Sopper, 1969). Boggs and Sun (2011) conclude that the effects of vegetation removal on stream flow are most pronounced during the growing seasons when the contrast between ET from a vegetated surface and from an urbanized surface is the highest. Therefore, it is plausible that replacing paddy fields with high ET with urban land uses (e.g., lawns or impermeable surfaces) with low ET may result in similar effects as forest removal during urbanization. Future studies should examine the seasonality of the trend of base-flow change to confirm the effects of rice paddy conversion on base-flow and groundwater change.

\subsection{Human factors affecting water balances}

The landscape and stream networks of the QRB have been altered for thousands of years by humans. Our water balance analysis used a holistic approach to examine the natural rainfall-runoff relationships at the watershed scale with minimum attention to human water supply and use within the watershed. Currently, the QRB provides important ecosystem services such as drought/flood prevention, crop irrigation, recreation, tourism, and emergency drinking water supply to local communities. Patterns of groundwater withdrawal from local acquirers and inter-basin transfers are changing in the study basin as the speed of urbanization increases (Du et al., 2012; Zhou et al., 2014). To meet the increasing demand on water supply and flood controls by the urbanized communities, ponds, reservoirs, and drainage canals have been built. There are over 20 small reservoirs with the basin. These landuse patterns have undoubtedly further complicated the quantification of water balances for a large basin (Hao et al., 2015) since each land-use change factor might have affected different hydrologic components. Future studies should focus on process-based understanding of how land conversions affect ET processes and how this effect manifests at the watershed in affecting storm flow and base flow. In addition, inter-basin transfers must be addressed to reduce potential water balance errors by full accounting water supply and use within and across the QRB.

\section{Conclusions}

Using long-term hydrometeorological records, landcover/land-use change information, and remote sensingbased biophysical and evapotranspiration data, this case study showed that stream-flow rates, both high flows and low flows, in the Qinhuai River basin increased from 1986 
to 2013. A significant increase in stream flow and a decrease in ET were detected in the study basin and the changes were considered to be associated with urbanization, characterized by the shrinkage of rice paddy fields and an increase in impervious surface area. Urbanization that resulted in a reduction in LAI during the peak growing season overwhelmed the hydrological effects of climate warming and precipitation variability during the study period. The importance of rice paddy fields in regulating ET and hydrologic responses to disturbance has been underestimated in previous similar studies. There is a need in research to fully understand the ecohydrological processes that control the effects of land conversions on land surface energy and water balances at multiple scales. Models for assessing the ecosystem service function (e.g., climate cooling, flood retention) of rice paddy fields must include proper algorithms describing the hydrological processes including ET that links water and energy balances.

Rice cultivations have been practiced for thousands of years around the world. However, converting rice paddy fields to other uses in southern China and East Asia has been on the rise in a changing climate and changing demographics. Our study indicates that urbanization will likely increase the risk of flooding, heat islands, and social vulnerability due to the loss of ecosystem services of rice paddies. Minimizing and mitigating the hydrologic and environmental impacts of converting paddy fields downstream, while maintaining resource sustainability, requires an integrated watershed management approach that involves careful urban planning (Dunne and Leopold, 1978), landscape design (Dietz and Clausen, 2008), and irrigation management (Park et al., 2009).

Acknowledgements. This study was supported by the Natural Science Foundation of China (71373130), the Jiangsu Key Laboratory of Agricultural Meteorology Fund (no. KYQ1201), the National Key Basic Research Program of China (2013CB430200, 2013CB430206), and IceMe of NUIST. Partial support was from the Southern Research Station, USDA Forest Service.

Edited by: F. Tian

\section{References}

Allen, R. G., Smith, M., Perrier, A., and Pereira, L. S.: An update for the definition of reference evapotranspiration, ICID Bull., 43, 1-34, 1994.

Arnold, C. L. and Gibbons, C. J.: Impervious surface coverage: the emergence of a key environmental indicator, Am. Planners Assoc. J., 62, 243-258, 1996.

Barron, O. V., Barr, A. D., and Donn, M. J.: Effect of urbanisation on the water balance of a catchment with shallow groundwater, J. Hydrol., 485, 162-176, doi:10.1016/j.jhydrol.2012.04.027, 2013.
Bledsoe, B. P. and Watson, C. C.: Effects of urbanization on channel instability, J. Am. Water Resour. Assess., 37, 255-270, doi:10.1111/j.1752-1688.2001.tb00966.x, 2001.

Boggs, J. L. and Sun, G.: Urbanization alters watershed hydrology in the Piedmont of North Carolina, Ecohydrology, 4, 256-264, doi:10.1002/Eco.198, 2011.

Brath, A., Montanari, A., and Moretti, G.: Assessing the effect on flood frequency of land use change via hydrological simulation (with uncertainty), J. Hydrol., 324, 141-153, doi:10.1016/j.jhydrol.2005.10.001, 2006.

Caldwell, P. V., Sun, G., McNulty, S. G., Cohen, E. C., and Myers, J. A. M.: Impacts of impervious cover, water withdrawals, and climate change on river flows in the conterminous US, Hydrol. Earth Syst. Sci., 16, 2839-2857, doi:10.5194/hess-16-28392012, 2012.

Chen, A. L., Du, J. K.: Simulation and forecast of land cover pattern in Qinhuai River Basin based on the CAMarkov model, Remote Sens. Land Resour., 26(2): 184-189, doi:10.6046/gtzyyg.2014.02.29, 2014.

Dietz, M. E. and Clausen, J. C.: Stormwater runoff and export changes with development in a traditional and low impact subdivision, J. Environ.Manage., 87, 560-566, doi:10.1016/j.jenvman.2007.03.026, 2008.

Du, J. K., Li, C., Rui, H., Li, Q., Zheng, D., Xu, Y. and Hu, S.: The change detection of impervious surface and its impact on runoff in the Qinhuai River Basin, China, 19th International Conference on Geoinformatics IEEE, 1-5, 2011.

Du, J. K., Qian, L., Rui, H. Y., Zuo, T. H., Zheng, D. P., Xu, Y. P., and $\mathrm{Xu}, \mathrm{C}$. Y.: Assessing the effects of urbanization on annual runoff and flood events using an integrated hydrological modeling system for Qinhuai River basin, China, J. Hydrol., 464, 127139, doi:10.1016/j.jhydrol.2012.06.057, 2012.

Dunne, T. and Leopold, L.: Water in environmental planning, New York, W. H. Freeman and Company Press, New York, 646-649, 1978.

Dow, C. L. and DeWalle, D. R.: Trends in evaporation and Bowen ratio on urbanizing watersheds in eastern United States, Water Resour. Res., 36, 1835-1843, doi:10.1029/2000wr900062, 2000.

Foley, J. A., DeFries, R., Asner, G. P., Barford, C., Bonan, G., Carpenter, S. R., Chapin, F. S., Coe, M. T., Daily, G. C., Gibbs, H. K., Helkowski, J. H., Holloway, T., Howard, E. A., Kucharik, C. J., Monfreda, C., Patz, J. A., Prentice, I. C., Ramankutty, N., and Snyder, P. K.: Global consequences of land use, Science, 309, 570-574, doi:10.1126/science.1111772, 2005.

Gilbert, R. O.: Statistical methods for environmental pollution monitoring New York, VanNostrand Reinhold Press, New York, 1-4, 1987.

Gong, P., Wang, J., Yu, L., Zhao, Y. C., Zhao, Y. Y., Liang, L., Niu, Z. G., Huang, X. M., Fu, H. H., Liu, S., Li, C. C., Li, X. Y., Fu, W., Liu, C. X., Xu, Y., Wang, X. Y., Cheng, Q., Hu, L. Y., Yao, W. B., Zhang, H., Zhu, P., Zhao, Z. Y., Zhang, H. Y., Zheng, Y. M., Ji, L.Y., Zhang, Y. W., Chen, H., Yan, A., Guo, J. H., Yu, L., Wang, L., Liu, X. J., Shi, T. T., Zhu, M. H., Chen, Y. L., Yang, G. W., Tang, P., Xu, B., Ciri, C., Clinton, N., Zhu, Z. L., Chen, J., and Chen, J.: Finer resolution observation and monitoring of global land cover: first mapping results with Landsat TM and ETM+ data, Int. J. Remote Sens., 34, 2607-2654, 2013. 
Gu, C., Hu, L., Zhang, X., Wang, X., and Guo, J.: Climate change and urbanization in the Yangtze River Delta, Habitat Int., 35, 544-552, 2011.

Hao, L., Sun, G., Liu, Y., and Qian, H.: Integrated modeling of water supply and demand under management options and climate change scenarios in Chifeng City, China, J. Am. Water Resour. Assess., 51, 655-671, doi:10.1111/1752-1688.12311, 2015.

He, B., Wang, Y., Takase, K., Mouri, G., and Razafindrabe, B. H. N.: Estimating Land Use Impacts on Regional Scale Urban Water Balance and Groundwater Recharge, Water Resour. Manag., 23, 1863-1873, doi:10.1007/s11269-008-9357-2, 2009.

He, J. F., Liu, J. Y., Zhuang, D. F., Zhang, W., and Liu, M. L.: Assessing the effect of land use/land cover change on the change of urban heat island intensity, Theor. Appl. Climatol., 90, 217-226, doi:10.1007/s00704-006-0273-1, 2007.

Jacobson, C. R.: Identification and quantification of the hydrological impacts of imperviousness in urban catchments: A review, J. Environ. Manage., 92, 1438-1448, 2011.

Jones, R. N., Chiew, F. H. S., Boughton, W. C., and Zhang, L.: Estimating the sensitivity of mean annual runoff to climate change using selected hydrological models, Adv. Water Resour., 29, 1419-1429, doi:10.1016/j.advwatres.2005.11.001, 2006.

Jonsson, P. and Eklundh, L.: TIMESAT - a program for analyzing time-series of satellite sensor data, Comput. Geosci-UK, 30, 833-845, 2004.

Kang, I. S., Park, J. I., and Singh, V. P.: Effect of urbanization on runoff characteristics of the On-Cheon stream watershed in $\mathrm{Pu}$ san, Korea, Hydrol. Process., 12, 351-363, 1998.

Kendall, M. G.: Rank correlation methods London: Charles Griffin Press, London, 10-35, 1975.

Kim, S. J., Kwon, H. J., Park, G. A., and Lee, M. S.: Assessment of land-use impact on streamflow via a grid-based modelling approach including paddy fields, Hydrol. Process., 19, 3801-3817, doi:10.1002/Hyp.5982, 2005

Kim, Y. J., Kim, H. D., and Jeon, J. H.: Characteristics of Water Budget Components in Paddy Rice Field under the Asian Monsoon Climate: Application of HSPF-Paddy Model, Water-Sui., 6, 2041-2055, doi:10.3390/W6072041, 2014

Li, L.-J., Zhang, L., Wang, H., Wang, J., Yang, J.-W., Jiang, D.J., Li, J.-Y., and Qin, D.-Y.: Assessing the impact of climate variability and human activities on streamflow from the Wuding River basin in China, Hydrol. Process., 21, 3485-3491, doi:10.1002/hyp.6485, 2007.

Liu, Y., Zhou, Y., Ju, W., Chen, J., Wang, S., He, H., Wang, H., Guan, D., Zhao, F., Li, Y., and Hao, Y.: Evapotranspiration and water yield over China's landmass from 2000 to 2010, Hydrol. Earth Syst. Sci., 17, 4957-4980, doi:10.5194/hess-17-49572013, 2013.

Lull, H. W. and Sopper, W. E.: Hydrologic effects from urbanization of forested watersheds in the Northeast, USDA Forest Service Research Paper NE-146, Northeastern Forest Experiment Station, 1969.

Ma, H. A., Yang, D. W., Tan, S. K., Gao, B., and Hu, Q. F.: Impact of climate variability and human activity on streamflow decrease in the Miyun Reservoir catchment, J. Hydrol., 389, $317-$ 324, doi:10.1016/j.jhydrol.2010.06.010, 2010.

Mann, H. B.: Non-parametric test against trend, Econometrica, 13, 245-259, 1945.
McDonald, R. I., Green, P., Balk, D., Fekete, B. M., Revenga, C., Todd, M., and Montgomery, M.: Urban growth, climate change, and freshwater availability, P. Natl. Acad. Sci. USA, 108, 63126317, doi:10.1073/pnas.1011615108, 2011.

Miller, J. D., Kim, H., Kjeldsen, T. R., Packman, J., Grebby, S., and Dearden, R.: Assessing the impact of urbanization on storm runoff in a pen-urban catchment using historical change in impervious cover, J. Hydrol., 515, 59-70, doi:10.1016/j.jhydrol.2014.04.011, 2014.

Mu, Q. Z., Zhao, M. S., and Running, S. W.: Improvements to a MODIS global terrestrial evapotranspiration algorithm, Remote Sens. Environ., 115, 1781-1800, doi:10.1016/j.rse.2011.02.019, 2011.

Ott, B. and Uhlenbrook, S.: Quantifying the impact of land-use changes at the event and seasonal time scale using a processoriented catchment model, Hydrol. Earth Syst. Sci., 8, 62-78, doi:10.5194/hess-8-62-2004, 2004.

Paul, M. J. and Meyer, J. L.: Streams in the urban landscape, Annu. Rev. Ecol. Syst., 32, 333-365, 2001.

Price, K., Jackson, C. R., Parker, A. J., Reitan, T., Dowd, J., and Cyterski, M.: Effects of watershed land use and geomorphology on stream low flows during severe drought conditions in the southern Blue Ridge Mountains, Georgia and North Carolina, United States, Water Resour. Res., 47, W02516, doi:10.1029/2010wr009340, 2011.

Sakaguchi, A., Eguchi, S., and Kasuya, M.: Examination of the water balance of irrigated paddy fields in SWAT 2009 using the curve number procedure and the pothole module, Soil Sci. Plant Nutr., 60, 551-564, doi:10.1080/00380768.2014.919834, 2014.

Sun, G., McNulty, S. G., Lu, J., Amatya, D. M., Liang, Y., and Kolka, R. K.: Regional annual water yield from forest lands and its response to potential deforestation across the southeastern United States, J. Hydrol., 308, 258-268, doi:10.1016/j.jhydrol.2004.11.021, 2005.

Sun, G., Alstad, K., Chen, J. Q., Chen, S. P., Ford, C. R., Lin, G. H., Liu, C. F., Lu, N., McNulty, S. G., Miao, H. X., Noormets, A., Vose, J. M., Wilske, B., Zeppel, M., Zhang, Y., and Zhang, Z. Q.: A general predictive model for estimating monthly ecosystem evapotranspiration, Ecohydrology, 4, 245255, doi:10.1002/Eco.194, 2011a.

Sun, G., Caldwell, P., Noormets, A., McNulty, S. G., Cohen, E., Myers, J. M., Domec, J. C., Treasure, E., Mu, Q. Z., Xiao, J. F., John, R., and Chen, J. Q.: Upscaling key ecosystem functions across the conterminous United States by a water-centric ecosystem model, J. Geophys. Res-Biogeosci., 116, G00J05, doi:10.1029/2010jg001573, 2011b.

Sun, G. and Lockaby, B. G.: Chapter 3: Water quantity and quality at the urban-rural interface, edited by: Laband, D. N., Lockaby, B. G., and Zipperer, W., Urban-Rural Interfaces: Linking People and Nature, ASACSS, SSAmerica, Madison, WI, 26-45, 2012.

Tang, L. H., Yang, D. W., Hu, H. P., and Gao, B.: Detecting the effect of land-use change on streamflow, sediment and nutrient losses by distributed hydrological simulation, J. Hydrol., 409, 172-182, doi:10.1016/j.jhydrol.2011.08.015, 2011.

Taylor, C. J., Pedregal, D. J., Young, P. C., and Tych, W.: Environmental time series analysis and forecasting with the Captain toolbox, Environ. Modell. Softw., 22, 797-814, doi:10.1016/j.envsoft.2006.03.002, 2007. 
Tsai, M. H.: The Multi-functional roles of paddy field irrigation in Taiwan, Proceedings of the pre-symposium for the third world water forum (WWF3), 217-220, 2002.

Vogel, R. M. and Fennessey, N. M.: L-Moment Diagrams Should Replace Product Moment Diagrams, Water Resour. Res., 29, 1745-1752, 1993.

Wahl, K. L. and Wahl, T. L.:Determining the flow of Comal Springs at New Braunfels, Texas, Texas Water '95, American Society of Civil Engineers (San Antonio, Texas), 16-17 August, 77-86, 1995.

Wang, Y. J., Lv, H. J., Shi, Y. F., and Jiang, T.: Impacts of land use changes on hydrological processes in an urbanized basin: a case study in the Qinhuai River Basin, J. Natl. Resour., 24, 30-36, 2009.

Wei, X. H. and Zhang, M. F.: Quantifying streamflow change caused by forest disturbance at a large spatial scale: A single watershed study, Water Resour. Res., 46, W12525, doi:10.1029/2010wr009250, 2010.

Wu, R. S., Sue, W. R., and Chang, J. D.: A simulation model for investigating the effects of rice paddy fields on runoff system In: Zerger A and Argent RM (eds) MODSIM97 International Congress on Modelling and Simulation, Modelling and Simulation Society of Australia and New Zealand, 422-427, 1997.
Xiao, Y., An, K., Xie, G., and Lu, C.: Evaluation of Ecosystem Services Provided by 10 Typical Rice Paddies in China, J. Resour Ecol., 2, 328-337, 2011.

Yang, L., Tian, F. Q., Smith, J. A., and Hu, H. P.: Urban Signatures in the Spatial Clustering of Summer Heavy Rainfall Events over the Beijing Metropolitan Region, J. Geophys. Res.-Atmos., 119, 1203-1217, doi:10.1002/2013JD020762, 2013.

Yuan, H., Dai, Y. J., Xiao, Z. Q., Ji, D. Y., and Shangguan, W.: Reprocessing the MODIS Leaf Area Index products for land surface and climate modelling, Remote Sens. Environ., 115, 1171-1187, doi:10.1016/j.rse.2011.01.001, 2011.

Zhao, L., Lee, X., Smith, R. B., and Oleson, K.: Strong contributions of local background climate to urban heat islands, Nature, 511, 216-219, doi:10.1038/Nature13462, 2014.

Zhou, D., Zhao, S., Liu, S., Zhang, L., and Zhu, C.: Surface urban heat island in China's 32 major cities: Spatial patterns and drivers, Remote Sens. Environ., 152, 51-61, 2014. 